\section{FINANCIAMIENTO DE ENFERMEDADES RARAS O HUÉRFANAS: UNA TAREA PENDIENTE}

\section{FINANCING FOR RARE OR ORPHAN DISEASES, A THING TO DO}

\author{
Akram Hernández-Vásquez ${ }^{1, a}$, \\ Juan Rubilar-González ${ }^{1, b}$, Nilthon Pisfil-Benites ${ }^{1, c}$
}

Sr. Editor. La Constitución Política del Perú, en su artículo 7, señala que todos tienen derecho a la protección de su salud y que es el Estado quien determina la política nacional de salud, es así, que específicamente el Gobierno mediante Ley $29698^{(1)}$ declaró el interés nacional por la prevención, el diagnóstico, la atención integral de salud y la rehabilitación de las personas que padecen enfermedades raras o huérfanas.

Dicha Ley define que: Las enfermedades raras 0 huérfanas, incluidas las de origen genético, son aquellas enfermedades con peligro de muerte o de invalidez crónica, que tienen una frecuencia baja, presentan muchas dificultades para ser diagnosticadas y efectuar su seguimiento, tienen un origen desconocido en la mayoría de los casos que conllevan múltiples problemas sociales y con escasos datos epidemiológicos.

Por consideración de Política Nacional, la Ley 29344, Ley Marco de Aseguramiento Universal en Salud, se estableció que aquellas enfermedades de alto costo que no están incluidas en el Plan Esencial de Aseguramiento en Salud puedan ser financiadas con el Fondo Intangible Solidario de Salud (FISSAL), el cual fue creado en el año 2012 como una entidad de derecho privado para complementar las funciones del Seguro Integral de Salud en el financiamiento de las enfermedades de alto costo y las raras o huérfanas. Sin embargo, al advertirse que inicialmente el soporte financiero era insuficiente, mediante Ley 29761 se le otorga al FISSAL la categoría de Institución Administradora de Fondos de Aseguramiento en Salud con un aumento progresivo del financiamiento y cobertura de atenciones que, a la fecha, no llega a ser el esperado y que en definitiva ha ido a costear predominantemente los tipos de cáncer más comunes y la insuficiencia renal crónica, dejando de lado el financiamiento de las enfermedades raras o huérfanas ${ }^{(2,3)}$.

\footnotetext{
Universidad de Chile. Chile.

a Médico cirujano; ${ }^{\text {b }}$ sociólogo; ${ }^{\mathrm{c}}$ contador público.

Recibido: 26-03-14 Aprobado: 02-04-14
}

Citar como: Hernández-Vásquez A, Rubilar-González J, Pisfil-Benites N. Financiamiento de enfermedades raras o huérfanas: una tarea pendiente [carta]. Rev Peru Med Exp Salud Publica. 2014;31(2):393.
Recordemos que la lógica tradicional de los seguros públicos y las políticas en salud se basan en la solidaridad y enfoque económico, bajo esa lógica y acorde con las disposiciones de la Ley 29698, el Ministerio de Salud, mediante Resolución Ministerial 691-2012/ MINSA, conforma la Comisión Sectorial para definir las enfermedades de alto costo y huérfanas, la misma que luego de una extensión de vigencia de la citada comisión, materializa en la Resolución Ministerial 151-2014/MINSA un listado de 399 enfermedades raras o huérfanas, clasificadas en cuatro grupos, según criterios de prioridad y determinando el financiamiento inicial para únicamente ocho enfermedades dentro del grupo considerado de muy alta prioridad (4). Con ello, la ansiada cobertura a estas enfermedades no se generalizó, solo se relegó a un grupo de enfermedades, haciendo caso omiso a otras y condicionando el acceso al resultado de la evaluación del Sistema de Focalización de Hogares, el que muchas veces dista de la realidad socioeconómica de los usuarios (5).

En suma, si bien no es posible financiar todas las enfermedades huérfanas o raras debido a los costos muy elevados, es el punto inicial de un complejo desafío que permita avanzar hacia la justicia y equidad en el acceso a la salud en una sociedad que considera de manera general a la salud como un bien público, pero que en el caso de las enfermedades huérfanas o raras estaría siendo considerado como un bien privado de aquellos que por el azar de la vida padecen estas enfermedades.

Fuentes de financiamiento: autofinanciado.

Conflictos de interés: los autores declaran no tener conflictos de interés.

\section{REFERENCIAS BIBLIOGRÁFICAS}

1. Perú, Congreso de la República. Ley que declara de interés nacional y preferente atención el tratamiento de personas que padecen enfermedades raras o huérfanas, 2011. Ley 29698. 26 de mayo del 2011.

2. Perú, Ministerio de Salud, Seguro Integral de Salud. Resolución Jefatural 143-2012/SIS. 17 de setiembre del 2012.

3. Perú, Ministerio de Salud. Resolución Ministerial 325-2012/ MINSA. 24 de abril del 2012.

4. Perú, Ministerio de Salud. Resolución Ministerial 151-2014/ MINSA. 21 de febrero del 2014

5. Martínez B, Henríquez C, Gutiérrez N, Gómez Vasallo C, Cortés García CM, Córdoba Mendoza PA, et al. Pobreza, desigualdad y salud en América Latina. Buenos Aires: CLACSO; 2013.

Correspondencia: Akram Hernández Vásquez

Dirección: Av. España 683, Departamento 814, Santiago Centro, Chile Teléfono: (0056) 953211215

Correo electrónico:akram.hernandez.v@upch.pe 